\title{
Three new species of Hypoxylon and new records of Xylariales from Panama
}

\author{
Cedeño-Sanchez $M^{1,2,3}$, Wendt $L^{4,5}$, Stadler $M^{4,5}$, Mejía $L C^{1,3^{*}}$
}

${ }^{1}$ Centro de Biodiversidad y Descubrimiento de Drogas, Instituto de Investigaciones Científicas y Servicios de Alta Tecnología (INDICASAT-AIP), Panamá

${ }^{2}$ Programa de Maestría en Ciencias Biológicas, Universidad de Panamá, Panamá

${ }^{3}$ Smithsonian Tropical Research Institute (STRI), Panama

${ }^{4}$ Department Microbial Drugs, Helmholtz-Zentrum für Infektionsforschung GmbH, Inhoffenstrasse 7, 38124 Braunscheweig, Germany

${ }^{5}$ German Center for Infection Research (DZIF), partner site Hannover- Braunscheweig, 38124 Braunscheweig, Germany

Cedeño-Sanchez M, Wendt L, Stadler M, Mejía LC 2020 - Three new species of Hypoxylon and new records of Xylariales from Panama. Mycosphere 11(1), 1457-1476, Doi 10.5943/mycosphere/11/1/9

\begin{abstract}
Three new species of Hypoxylon (Hypoxylaceae, Xylariales) are described based on a polyphasic approach that included morphological examination, molecular phylogeny and chemotaxonomic studies of specimens collected in Panama. Specifically, we compared the sexual morph (stromata, asci, and ascospores) of the specimens collected with known species of Hypoxylon and inferred a phylogeny of this genus based on a Randomized Axelerated Maximum Likelihood (RAxML) analysis of partial $\beta$-tubulin (TUB2) DNA sequences and the internal transcribed spacer regions (ITS). Hypoxylon baruense sp. nov. is phylogenetically related to $H$. subgilvum but differs in the shape of stromata, and by having larger ascospores and a smooth perispore. Hypoxylon bellicolor sp. nov. is phylogenetically well differentiated, featuring effusedpulvinate stromata with orange granules and ostioles lower than the stromatal surface. Hypoxylon sporistriatatunicum sp. nov., is phylogenetically related to $H$. shearii var. minor but differs in the shape of the stromata, in having ostioles higher than the stromatal surface, and in having larger ascospores. The secondary metabolite profiles of these species were studied by HPLC-DAD-MS and these correspond to the results of the morphological and phylogenetic studies. Additionally, we also report Amphirosellinia evansii, $H$. howeanum, $H$. cinnabarinum and Stilbohypoxylon quisquiliarum from Panama for the first time and Citrus sinensis as a new host of $H$. cinnabarinum. With this work, the number of species of Xylariales and Hypoxylon reported from Panama have increased to 103 and 18, respectively.
\end{abstract}

Key words - Biodiversity - Fungi - Sordariomycetes - Hypoxylaceae

\section{Introduction}

The order Xylariales comprises 26 families that include approx. 2,500 species in 210 genera (Hongsanan et al. 2017). Species in this order are common worldwide, though the highest diversity of Xylariales is found in the tropics (see Dayarathne et al. 2017, Li et al. 2017, Sir et al. 2016b for 
recent records of new tropical taxa). Of the 26 families of Xylariales (Helaly et al. 2018), the Xylariaceae and Hypoxylaceae are two of the most diverse and include the specimens studied in this work. The Xylariaceae (Tul. \& C. Tul. [as “Xylariei”] Selects fung Carpol (Paris) 2: 3 (1863) emend M. Stadler \& L. Wendt) is second to Amphisphaeriaceae (Xylariales) in terms of species richness, and comprises 823 species in 32 genera (Wendt et al. 2018). Species of Xylariaceae produce a geniculosporium-like asexual state, and in general, their stromata do not contain extractable pigments in 10\% KOH (Wendt et al. 2018). Recently, 674 species were segregated from Xylariaceae and distributed into three families (Graphostromataceae, Hypoxylaceae, and Lopadostomataceae) while several more were segregated but are currently considered incertae sedis within Xylariales and Sordariomycetes, due to the lack of sufficient molecular data and information on the types of the asexual morph (Wendt et al. 2018). The Hypoxylaceae contains more than 360 species in 18 genera including recently described new taxa (Wendt et al. 2018, Daranagama et al. 2018, Lambert et al. 2019, De Long et al. 2019, Sir et al. 2019). The recent update of Sordariomycete families (Hyde et al. 2020) even listed 422 species in 19 genera.

The first records of Xylariales from Panama were based on specimens collected in Barro Colorado Island, Panama Canal Area, in the 1920s (Weston 1933, Standley 1933), and included 11 species of Hypoxylon, but only four of them are currently accepted in this genus: $H$. haematostroma, $H$. fuscum, $H$. hypomiltum, and $H$. rubiginosum). These records were followed by the reports of $H$. subgilvum and $H$. dieckmanii from the Panama Canal Area by Dennis in 1956, 1970 respectively. More recent collections were recorded for western Panama by Carmona et al. 2009 (H. anthochroum, H. crocopeplum, H. investiens, H. fendleri, and H. lividipigmentum), Piepenbring et al. 2012 (H. pelliculosum), and Kuhnert et al. 2015 (H. trugodes). Despite these studies, the reports of Xylariales from Panama are very scarce; only 95 species have been reported in the country for this highly diverse order (Piepenbring 2013). Recent surveys of Sordariomycetes in Panama conducted by our research group suggest that many species of Xylariales remain to be described. Here we present new records of Xylariales from Panama and the description of three new species of Hypoxylon based on comparative morphology, molecular phylogeny, and chemotaxonomy.

This study was based on specimens collected at six sites in the Republic of Panama and they are characterized based on a polyphasic approach (morphological, DNA based phylogeny and secondary metabolite profiling).

\section{Materials \& Methods}

\section{Collection of specimens and preparation of cultures}

Since the scope of this study was to make an inventory of Hypoxylon, a genus whose stromata almost exclusively occur on woody, dicotyledonous angiosperms, the collection work focused on the forests that are known for a high diversity of such potential hosts. Two sites in the Panama Canal Area: Soberania National Park (SNP) and Camino de Cruces Park (CCP). Four sites in the western province of Chiriquí: Barú Volcano National Park (BVNP), La Concepción, Sortová, and La Amistad International Park (PILA, Chiriquí side). Four of these sites (SNP, CCP, Sortová and Concepción) are localized in lowlands at $<700$ meters above sea level (m.a.s.l.) and two at elevations higher than 1500 m.a.s.l. (PILA and BVNP).

Each of the sites were visited at least one time and specimens of fungi with typical morphological characters of Xylariaceae and Hypoxylaceae were collected, placed in paper bags, dried overnight at ambient temperature to remove excess humidity and transported to the laboratory for detailed observation and isolation of pure cultures. In the laboratory, perithecia were removed from the stromata using a sterile scalpel under a dissecting stereomicroscope (Nikon SMZ800, Melville, NY, USA), placed on a microscope slide with $50 \mu$ l of sterile water and crushed to release ascospores. Thereafter, $10 \mu \mathrm{l}$ of the ascospore suspension were transferred to Petri dishes with potato dextrose agar (PDA) supplemented with rifampicin $(P D A+r)$. After 24 hours the media were observed for sporulation and monosporic cultures were generated. In rare cases, cultures were 
generated from multiple germinated spores or cultured from a small piece of the stromata. The cultures were preserved in $10 \%$ glycerol at $-20^{\circ} \mathrm{C}$ and maintained in corn meal agar (CMA) slants at $8^{\circ} \mathrm{C}$. Cultures were grown in: Potato dextrose agar (PDA), $2 \%$ malt extract agar (2\%MEA), V8 agar, oatmeal agar (OA), and potato carrot agar (PCA).

\section{Morphological observations}

Sexual structures of the collected specimens were extracted from fresh material, immersed in distilled water and $10 \% \mathrm{KOH}$ respectively, and size measurements were performed. Melzer's reagent was used to test the presence of an amyloid reaction of the apical apparatus. The color of the stromata and the extractable pigments were reported following the codes according to Rayner (1970). The stroma and perithecia of each specimen were photographed with a camera (ZEISS Axiocam ICc 5, Jena, Germany) connected to the microscope (ZEISS Axio Scope.A1, Germany). Asci and ascospores were observed, photographed, and measured using an Olympus BX53 microscope equipped with an Olympus DP73 camera and the CellSens Dimensions Software (Olympus, Japan). Specimens were preliminary identified morphologically using the key to species of Hypoxylon by Ju \& Rogers (1996), Fournier et al. (2015) and Sir et al. (2016a), and in the case of Stilbohypoxylon by Petrini (2004). Further identification was accomplished using both, morphological and phylogenetic analyses (see below). Dried specimens were deposited in the herbarium of the Autonomous University of Chiriquí, Faculty of Natural and Exact Sciences, Chiriquí, Panama (UCH).

\section{DNA extraction, amplification, and sequencing}

DNA was extracted from 5 days old mycelial cultures grown on PDA media. Approximately a square centimeter of mycelium, taken from the growth front of the cultures was scraped off the surface of the medium and transferred to an extraction tube. The DNA was extracted using the Gentra Puregene Tissue kit (QIAGEN, Germany) following the manufacturer's instructions. The TUB2 gene region was amplified using the primers T1 and T22 (O’Donnell \& Cigelnik 1997). Amplifications were performed in $25 \mu$ l assays containing: 5-15 ng of genomic DNA, $200 \mu \mathrm{M}$ of each dNTP, 2.5 units of Taq DNA Polymerase (QIAGEN, Germany), $2 \mu \mathrm{M}$ of each primer and 10x buffer with $15 \mathrm{mM} \mathrm{MgCl2}$; using the iCycler thermal cycler ABI 2720 (Applied Biosystems, USA) under the following reaction conditions: $5 \mathrm{~min}$ at $94^{\circ} \mathrm{C}$, followed by 32 cycles of $45 \mathrm{~s}$ at $94^{\circ} \mathrm{C}, 45 \mathrm{~s}$ at $50^{\circ} \mathrm{C}$, and $1.5 \mathrm{~min}$ at $72^{\circ} \mathrm{C}$, with a final extension period of $10 \mathrm{~min}$ at $72^{\circ} \mathrm{C}$. The ITS gene region was amplified according to Mejía et al. (2008).

PCR products were purified using ExoSAP-IT (USB, Cleveland, USA) following the manufacturer's instructions, and the purified DNA was used for further cycle sequencing reactions with the BigDye Terminator v 3.1 kit (Applied Biosystems, Life Technologies Corporation, Carlsbad CA). The cycle sequencing reactions were performed using the same PCR primers and for TUB2 additionally, the internal primers T2 and T12 (O’Donnell \& Cigelnik 1997). The reactions samples were purified with the Big Dye Xterminator kit and the PCR products were sequenced with an Applied Biosystems 3500 Genetic Analyzer (Life Technologies, Carlsbad, CA).

\section{Phylogenetic analysis}

DNA sequences of the new species were analyzed for quality and edited using the software Sequencher 5.1 (versión 5.1, Gene codes corporations, Ann Arbor, USA). The generated DNA sequences were collated against deposited sequences in the GenBank ${ }^{\circledR}$ database using the Basic Local Alignment Search Tool for Nucleotide sequences (Benson et al. 2013). Authentic ITS and TUB2 sequences of suitable Hypoxylon taxa from published studies were selected for the phylogenetic analyses (Table 1). Furthermore, the type species of prominent Hypoxylon sister genera were also included and Xylaria hypoxylon (Xylariaceae) was the outgroup. MAFFT alignments (G-INS-i, PAM 200/ k=2, GOP = 1.53, OV = 0.123; Katoh \& Kuma 2002) of the ITS and TUB2 sequence dataset were calculated respectively, using the MAFFT v7.017 plug-in of Geneious ${ }^{\circledR} 7.1 .9$ (http://www.geneious.com, Kearse et al. 2012). 
Table 1 List of strains used in the phylogenetic analyses. GenBank accession numbers for the ITS and TUB2 sequences are given. Strains derived from type specimens are labelled with T (holotype), IT (isotype), ET (epitype). Sequences derived from this study are highlighted in bold. Scientific names follow Index Fungorum (http://www.indexfungorum.org/).

\begin{tabular}{|c|c|c|c|c|c|c|}
\hline Species name & Strain & ITS & TUB2 & Location & Status & Reference \\
\hline $\begin{array}{l}\text { Annulohypoxyplon } \\
\text { truncatum }\end{array}$ & CBS 140778 & KY610419 & KX376352 & $\begin{array}{l}\text { Texas } \\
\text { (USA) }\end{array}$ & ET & Kuhnert et al. (2017) \\
\hline Daldinia concentrica & CBS 113277 & AY616683 & КС977274 & Germany & & $\begin{array}{l}\text { Triebel et al. (2005; } \\
\text { ITS), Kuhnert et al. } \\
\text { (2014; TUB2) }\end{array}$ \\
\hline $\begin{array}{l}\text { Hypomontagnella } \\
\text { monticulosa }\end{array}$ & MUCL 54604 & KY610404 & KX271273 & $\begin{array}{l}\text { French } \\
\text { Guiana }\end{array}$ & ET & Wendt et al. (2018) \\
\hline Hypoxylon addis & MUCL 52797 & КС968931 & КС977287 & Ethiopia & $\mathrm{T}$ & Kuhnert et al. (2014) \\
\hline Hypoxylon anthochroum & BCRC 34050 & JN660819 & AY951703 & Mexico & & Hsieh et al. (2005) \\
\hline $\begin{array}{l}\text { Hypoxylon baruense sp. } \\
\text { nov. }\end{array}$ & $\begin{array}{l}\text { MC66, ex } \\
\text { UCH9545 }\end{array}$ & MN056428 & MK908142 & Panama & & This study \\
\hline Hypoxylon begae & BCRC 34051 & JN660820 & AY951704 & $\begin{array}{l}\text { Hawaii } \\
\text { (USA) }\end{array}$ & & Hsieh et al. (2005) \\
\hline $\begin{array}{l}\text { Hypoxylon bellicolor sp. } \\
\text { nov. }\end{array}$ & $\begin{array}{l}\text { MC36, } \\
\text { UCH9543 }\end{array}$ & MN056425 & MK908139 & Panama & & This study \\
\hline Hypoxylon brevisporum & BCRC 33809 & JN660821 & AY951705 & Puerto Rico & & Hsieh et al. (2005) \\
\hline Hypoxylon calileguense & STMA 14059 & KU604566 & KU604579 & Argentina & & Sir et al. (2016a) \\
\hline Hypoxylon carneum & BCRC 34052 & JN660822 & AY951706 & France & & Hsieh et al. (2005) \\
\hline Hypoxylon cercidicola & CBS 119009 & KC968908 & KC977263 & France & & Kuhnert et al. (2014) \\
\hline Hypoxylon cinnabarinum & BCRC 34055 & JN979409 & AY951708 & Puerto Rico & & Hsieh et al. (2005) \\
\hline $\begin{array}{l}\text { Hypoxylon } \\
\text { cinnabarinum }\end{array}$ & $\begin{array}{l}\text { MC97, } \\
\text { UCH9546 }\end{array}$ & MN056429 & MK908143 & Panama & & This study \\
\hline Hypoxylon crocopeplum & BCRC 34056 & JN979410 & AY951710 & $\begin{array}{l}\text { Indiana } \\
\text { (USA) }\end{array}$ & & Hsieh et al. (2005) \\
\hline Hypoxylon dieckmanii & BCRC 34058 & JN979412 & AY951712 & Mexico & & Hsieh et al. (2005) \\
\hline Hypoxylon erythrostroma & MUCL 53759 & KC968910 & КС977296 & Martinique & & Kuhnert et al. (2014) \\
\hline Hypoxylon fendleri & BCRC 34064 & JN979418 & AY951718 & Taiwan & & Hsieh et al. (2005) \\
\hline Hypoxylon fendleri & $\begin{array}{l}\text { MC25, ex } \\
\text { UCH9552 }\end{array}$ & MN056423 & MK908137 & Panama & & This study \\
\hline Hypoxylon ferrugineum & CBS 141259 & KX090079 & KX090080 & Austria & & $\begin{array}{lr}\begin{array}{l}\text { Friebes \& } \\
(2016,\end{array} & \text { Wendelin } \\
\text { submission) } & \text { direct }\end{array}$ \\
\hline $\begin{array}{l}\text { Hypoxylon } \\
\text { flavoargillaceum }\end{array}$ & STMA 14062 & KU604577 & KU159532 & Argentina & & Sir et al. (2016a) \\
\hline Hypoxylon fragiforme & MUCL 51264 & KC477229 & KX271282 & Germany & ET & Wendt et al. (2018) \\
\hline Hypoxylon fraxinophilum & MUCL 54176 & КС968938 & КС977301 & France & ET & Kuhnert et al. (2014) \\
\hline $\begin{array}{l}\text { Hypoxylon } \\
\text { fulvosulphureum }\end{array}$ & $\begin{array}{l}\text { MFLUCC 13- } \\
0589\end{array}$ & КР401576 & КР401584 & Thailand & $\mathrm{T}$ & Sir et al. (2015) \\
\hline $\begin{array}{l}\text { Hypoxylon } \\
\text { fuscopurpureum }\end{array}$ & BCRC 34067 & JN979421 & AY951721 & $\begin{array}{l}\text { Virginia } \\
\text { (USA) }\end{array}$ & & Hsieh et al. (2005) \\
\hline Hypoxylon fuscum & CBS 113049 & KY610401 & KX271271 & France & ET & Wendt et al. (2018) \\
\hline $\begin{array}{l}\text { Hypoxylon } \\
\text { griseobrunneum }\end{array}$ & CBS 331.73 & KY610402 & КС977303 & India & $\mathrm{T}$ & $\begin{array}{l}\text { Kuhnert et al. (2014; } \\
\text { TUB2), Wendt et al. } \\
\text { (2018; ITS) }\end{array}$ \\
\hline $\begin{array}{l}\text { Hypoxylon } \\
\text { haematostroma }\end{array}$ & $\begin{array}{l}\text { MC34, ex } \\
\text { UCH9555 }\end{array}$ & MN056424 & MK908138 & Panama & & This study \\
\hline $\begin{array}{l}\text { Hypoxylon } \\
\text { haematostroma }\end{array}$ & MUCL 47600 & AM749924 & КС977279 & Panama & & Kuhnert et al. (2014) \\
\hline Hypoxylon howeanum & $\begin{array}{l}\text { MC62, ex } \\
\text { UCH9565 }\end{array}$ & MN056427 & MK908144 & Panama & & This study \\
\hline Hypoxylon howeanum & MC65 & MN056430 & MK908141 & Panama & & This study \\
\hline Hypoxylon howeanum & MUCL 47599 & AM749928 & КС977277 & Germany & & Kuhnert et al. (2014) \\
\hline Hypoxylon hypomiltum & MUCL 53312 & КС968914 & КС977298 & Guadeloupe & & Kuhnert et al. (2014) \\
\hline
\end{tabular}


Table 1 Continued.

\begin{tabular}{|c|c|c|c|c|c|c|}
\hline Species name & Strain & ITS & TUB2 & Location & Status & Reference \\
\hline Hypoxylon investiens & CBS 118183 & КС968925 & КС977270 & Malaysia & & Kuhnert et al. (2014) \\
\hline Hypoxylon jaklitschii & CBS 138916 & KM610290 & KM610304 & Sri Lanka & $\mathrm{T}$ & Kuhnert et al. (2015) \\
\hline Hypoxylon jecorinum & YMJ 39 & JN979429 & AY951731 & Mexico & & Hsieh et al. (2005) \\
\hline $\begin{array}{l}\text { Hypoxylon } \\
\text { lateripigmentum }\end{array}$ & MUCL 53304 & КС968933 & КС977290 & Martinique & $\mathrm{T}$ & Kuhnert et al. (2014) \\
\hline Hypoxylon lenormandii & STMA 14072 & KM610283 & KM610299 & Argentina & & Kuhnert et al.( 2015) \\
\hline Hypoxylon liviae & CBS 115282 & КС968922 & КС977265 & Norway & ET & Kuhnert et al. (2014) \\
\hline Hypoxylon lividicolor & BCRC 34076 & JN979432 & AY951734 & Taiwan & $\mathrm{T}$ & Hsieh et al. (2005) \\
\hline $\begin{array}{l}\text { Hypoxylon } \\
\text { lividipigmentum }\end{array}$ & BCRC 34077 & JN979433 & AY951735 & Mexico & IT & Hsieh et al. (2005) \\
\hline Hypoxylon macrosporum & BCRC 34078 & JN979434 & AY951736 & Canada & & Hsieh et al. (2005) \\
\hline Hypoxylon munkii & MUCL 53315 & KC968912 & KC977294 & Martinique & & Kuhnert et al. (2014) \\
\hline Hypoxylon musceum & MUCL 53765 & KC968926 & KC977280 & Guadeloupe & & Kuhnert et al. (2014) \\
\hline Hypoxylon ochraceum & MUCL 54625 & KC968937 & KC977300 & $\begin{array}{l}\text { Martinique } \\
\text { West }\end{array}$ & ET & Kuhnert et al. (2014) \\
\hline Hypoxylon papillatum & ATCC 58729 & KC968919 & KC977258 & $\begin{array}{l}\text { Virginia } \\
\text { (USA) }\end{array}$ & $\mathrm{T}$ & Kuhnert et al. (2014) \\
\hline Hypoxylon perforatum & MUCL 54174 & КС968936 & КС977299 & Japan & & Kuhnert et al. (2014) \\
\hline Hypoxylon petriniae & CBS 114746 & KY610405 & KX271274 & France & $\mathrm{T}$ & $\begin{array}{l}\text { Kuhnert et al. (2014; } \\
\text { TUB2), Wendt et al. } \\
\text { (2018; ITS) }\end{array}$ \\
\hline Hypoxylon pilgerianum & BCRC 34985 & JQ009310 & AY951744 & Taiwan & & Hsieh et al. (2005) \\
\hline $\begin{array}{l}\text { Hypoxylon } \\
\text { polyporoideum }\end{array}$ & BCRC 34088 & JQ009311 & AY951747 & Taiwan & & Hsieh et al. (2005) \\
\hline Hypoxylon porphyreum & CBS 119022 & KC968921 & KC977264 & France & & Kuhnert et al. (2014) \\
\hline Hypoxylon pulicicidum & MUCL 49879 & JX183075 & JX183072 & Martinique & $\mathrm{T}$ & Bills et al. (2012) \\
\hline Hypoxylon rickii & MUCL 53309 & KC968932 & КС977288 & Martinique & ET & Kuhnert et al. (2014) \\
\hline Hypoxylon rubiginosum & MUCL 52887 & KC477232 & KY624311 & Germany & ET & $\begin{array}{l}\text { Stadler et al (2013; } \\
\text { ITS), Wendt et al. } \\
(2018 ; \text { TUB2) }\end{array}$ \\
\hline Hypoxylon samuelsii & MUCL 51843 & КС968916 & KC977286 & Guadeloupe & ET & Kuhnert et al. (2014) \\
\hline $\begin{array}{l}\text { Hypoxylon shearii var. } \\
\text { minor }\end{array}$ & BCRC 34093 & EF026142 & AY951753 & Mexico & IT & Hsieh et al. (2005) \\
\hline Hypoxylon spegazzianum & STMA 14082 & KU604573 & KU604582 & Argentina & $\mathrm{T}$ & Sir et al. (2016a) \\
\hline $\begin{array}{l}\text { Hypoxylon } \\
\text { sporistriatatunicum sp. } \\
\text { nov. }\end{array}$ & $\begin{array}{l}\text { MC50, ex } \\
\text { UCH9542 }\end{array}$ & MN056426 & МК908140 & Panama & & This study \\
\hline Hypoxylon subgilvum & BCRC 34094 & JQ009314 & AY951754 & $\begin{array}{l}\text { Hawaii } \\
\text { (USA) }\end{array}$ & & Hsieh et al. (2005) \\
\hline Hypoxylon subrutiloides & F 202416 & FJ185304 & FJ185281 & $\begin{array}{l}\text { New } \\
\text { Zealand }\end{array}$ & & Platas et al. (2009) \\
\hline Hypoxylon ticinense & BCRC 34097 & JQ009317 & AY951757 & France & & Hsieh et al. (2005) \\
\hline Hypoxylon ulmophilum & BCRC 34100 & JQ009320 & AY951760 & $\begin{array}{l}\text { Primorsky } \\
\text { (Russia) }\end{array}$ & & Hsieh et al. (2005) \\
\hline Hypoxylon vogesiacum & CBS 115273 & КС968920 & KX271275 & France & & $\begin{array}{l}\text { Kuhnert et al. (2014; } \\
\text { ITS), Kuhnert et al. } \\
\text { (2017; TUB2) }\end{array}$ \\
\hline $\begin{array}{l}\text { Jackrogersella } \\
\text { multiformis }\end{array}$ & CBS 119016 & KC477234 & KX271262 & Germany & ET & Kuhnert et al. (2014) \\
\hline Pyrenopolyporus hunteri & MUCL 52673 & KY610421 & KU159530 & Ivory Coast & ET & Kuhnert et al. (2017) \\
\hline Xylaria hypoxylon & CBS 122620 & KY610407 & KX271279 & Sweden & ET & Wendt et al. (2018) \\
\hline
\end{tabular}

The obtained alignments were cured using the Castresana Lab Gblocks Server v0.91b at low stringency settings (allowance of smaller final blocks \& gap positions within the final blocks; http://molevol.cmima.csic.es/castresana/Gblocks_server.html, Talavera \& Castresana 2007, 
Castresana 2000) and flanking positions with missing sequence data was replenished with "?”. A modeltest $(\mathrm{N}=88)$ was performed for both cured alignments respectively, with default settings in jModeltest 2.1.10 v20160303 (Darriba et al. 2012), BIC values were calculated for all tested substitution models and the best substitution model for a combined alignment was chosen. The cured ITS and TUB2 alignment were concatenated, and a maximum likelihood analysis (ML) was performed with RAxML7.2.8 (Stamatakis 2006, 2014, Stamatakis \& Alachiotis 2010) starting with a complete random tree, GTR+G+I as substitution model and 1000 bootstrap replicates, carried out in Geneious ${ }^{\circledR}$.

The ML tree was rooted with Xylaria hypoxylon as outgroup, exported as scalable vector graphic (svg) and opened in Inkscape 0.92.3 (C) 1989, 1991 Free Software Foundation, Inc., https://www.inkscape.org) for layout implementation (Fig. 1).

\section{HPLC profiling}

Stromatal extracts were obtained by removal of small amounts of the stromata tissue, immersion in acetone and extraction in an ultrasonic bath at $40^{\circ} \mathrm{C}$ for $15 \mathrm{~min}$. The reaction tubes were centrifuged and the supernatant was used for chemical analyses using high performance liquid chromatography coupled with diode array and electrospray mass spectrometric detection (HPLC/DAD-ESIMS) as described in Kuhnert et al. (2017), and the gradient was the same as described by Surup et al. (2018). The mass spectra, UV-visible spectra and retention times were compared with an internal database comprising standards of known compounds from Xylariales to identify correlating peaks. The results are depicted in Fig. 5. Some characteristic metabolites are shown in Fig. 6.

\section{Results}

\section{Phylogenetic analyses}

For the phylogenetic analysis the ITS and TUB2 sequences of the eight collected Panamanian species were compared with sequences of 58 taxa, including sequences of many type and authentic species of Hypoxylon (Kuhnert et al. 2014, Wendt et al. 2018). Sequences of the type species of sister genera to Hypoxylon, namely Annulohypoxyplon truncatum, Daldinia concentrica, Hypomontagnella monticulosa, Jackrogersella multiformis and Pyrenopolyporus hunteri were included as well.

The MAFFT alignment of ITS and TUB2 consisted, respectively of 1672 and 2024 characters prior curing and 363 and 1085 after (21\% and 53\% of the original alignment length). Excluded flanking regions were [54-59], [99-113], [115-119], [125-136], [545-551], [591-603], [606-610], [620-625], [638-647], [651-656], [662-828], [835-848], [850-871], [895-911], [913-945], [962968], [970-975] and [1007-1018] for the ITS alignment; and [126-133], [197-202], [204-208], [421-431], [439-443], [450-487], [528-539], [548-561], [576-604], [674-721], [760-764], [886893], [895-955], [1034-1042], [1047-1341], [1343-1479], [1481-1735], [1737-1849], [1898-1905] and [1919-1936] for the TUB2 alignment. The modeltest identified $G T R+I+G$ as sixth and fifth best suited substitution model for the cured ITS $(-\ln (\mathrm{L})=5553, \mathrm{~K}=140, \mathrm{BIC}=11932)$ and TUB2 $(\ln (\mathrm{L})=13461, \mathrm{~K}=140, \mathrm{BIC}=27901)$ alignment, respectively and the best substitution model for the calculation of a ML tree based on the combined alignment of the cured ITS and TUB2 alignments (ITS-TUB2 alignment, length: 1448 characters). The RAxML analysis resulted in the ML tree depicted in Fig. 1 with a $-\ln (\mathrm{L})$ value of 19353 and a tree length of 8.2866 (model information: $\alpha=0.947863$; inv $=0.547936$; substitution rates: $\mathrm{A} \leftrightarrow \mathrm{C}=0.765339, \mathrm{~A} \leftrightarrow \mathrm{G}=$ 3.433984, $\mathrm{A} \leftrightarrow \mathrm{T}=1.232713, \mathrm{C} \leftrightarrow \mathrm{G}=0.519272, \mathrm{C} \leftrightarrow \mathrm{T}=5.779039, \mathrm{G} \leftrightarrow \mathrm{T}=1.000000$; base frequencies: $f \pi(\mathrm{A})=0.20635, f \pi(\mathrm{C})=0.301368, f \pi(\mathrm{G})=0.243091, f \pi(\mathrm{T})=0.249276)$.

The calculated ML tree showed strong bootstrap support for most of the terminal clades but lacked general support for the tree backbone. This issue has been observed in previous studies of Xylariales (Hsieh et al. 2005, Kuhnert et al. 2014, Wendt et al. 2018) and could possibly be overcome by including further phylogenetic markers and taxa. 


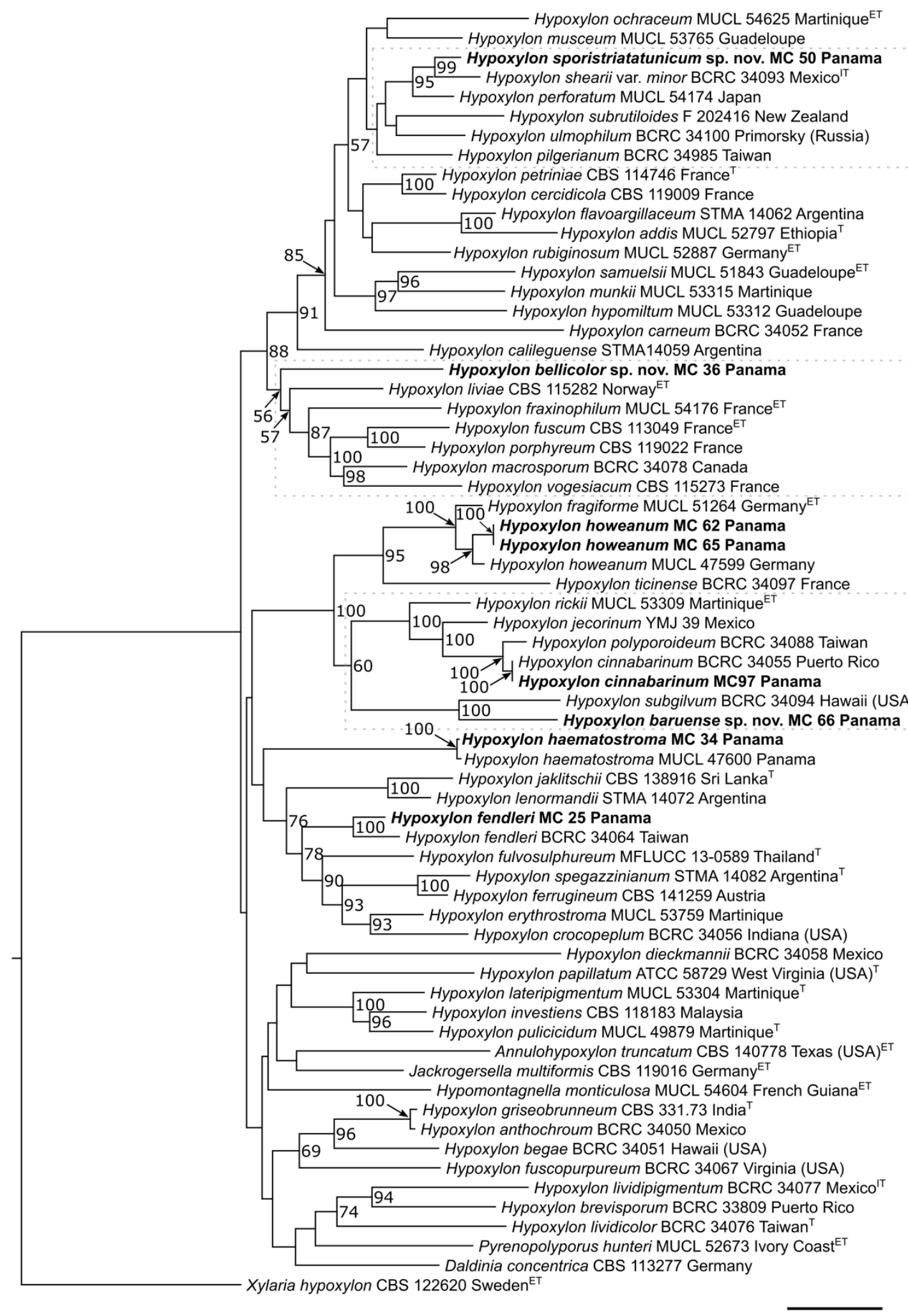

Figure 1 - Phylogenetic tree of Hypoxylon. Maximum Likelihood analysis (RaxML) inferred from a cured \& combined MAFFT alignment of ITS and TUB2 DNA sequences. Bootstrap support values from 1000 replicates were indicated at the respective nodes. The tree was rooted with Xylaria hypoxylon as outgroup and taxa derived from type material are indicated with superscripts ${ }^{\mathrm{T}}$ for holotype, ${ }^{\mathrm{ET}}$ for epitype, ${ }^{\mathrm{IT}}$ for isotype. Sequences highlighted in bold were derived from this study. 
The postulated new species of Hypoxylon clustered predominantly in fully supported clades. Hypoxylon baruense sp. nov. clustered with Hypoxylon subgilvum (BS 100\%) while $H$. sporistriatatunicum sp. nov. appears closely related to $H$. shearii var. minor (BS 99\%). Hypoxylon bellicolor sp. nov. occurred in a separate clade with only 56\% BS support. Hence, it is likely that closer relatives have still not been found as yet and further collections of new Hypoxylon species are needed for a better phylogenetic resolution. However, our DNA based analysis herein support our morphological observations and analysis of the secondary metabolites by HPLC and justify the erection as new species of Hypoxylon. Furthermore, the collected specimen of $H$. cinnabarinum (MC 97), H. fendleri (MC 25), H. haematostroma (MC 34) and H. howeanum (MC 62 \& 65), clustered respectively in fully supported clades with their reference taxon, which confirms their identification

\section{Description of new species of Hypoxylon}

Hypoxylon baruense M. Cedeño-Sanchez, L. Wendt \& L.C. Mejía sp. nov.

Fig. 2

Mycobank number: MB 832717; Facesoffungi number: FoF 07186

Etymology - Named after the Barú Volcano National Park, where the species was collected for the first time.

Stromata - effused-pulvinate, sessile, with inconspicuous perithecial mounds, $0.3-1.7 \mathrm{~cm}$ long x $0.2-1.3 \mathrm{~cm}$ broad x $0.2 \mathrm{~cm}$ thick ( $=1$ ); surface Rust (39), Blood Colour (3); with orange granules beneath the surface and between the perithecia; with $\mathrm{KOH}$-extractable pigments Greenish Yellow (16) or Luteous (12). Perithecia: obovoid to tubular, $0.3 \mathrm{~mm}$ broad x $0.5-0.6 \mathrm{~mm}$ high $(\mathrm{n}=6)$. Ostioles: lower than the stromatal surface. Asci: $120-157 \mu \mathrm{m}$ x $5-7 \mu \mathrm{m}(\mathrm{n}=6)$, with apical apparatus bluing in Melzer's reagent, $2-3.6 \mu \mathrm{m}$ long x 1-1.4 $\mu \mathrm{m}$ broad $(\mathrm{n}=5)$. Ascospores: dark brown, unicellular, ellipsoid-inequilateral, 10-15 × 5-7.6 $\mu \mathrm{m}(\mathrm{n}=50)$, with straight conspicuous germ slit less than spore-length; perispore indehiscent in $10 \% \mathrm{KOH}$, smooth.

Culture characteristics - Colonies on PDA covering a $60 \mathrm{~mm}$ Petri dish in 3 weeks, mycelium white above, reverse dark green, with concentric zones. No asexual morph observed in the culture media used i.e. PDA, 2\% MEA, V8 agar, oatmeal agar and potato carrot agar.

Secondary metabolites: Binaphthalene tetrol (BNT) as major component, mitorubrinol acetate as minor component and various unknown lipophilic components.

Distribution - Panama

Holotype - Panama, Chiriquí, Barú Volcano National Park, Quetzales trail, latitude 850'47.5" longitude 82³1'47.9", on dead trunk, 23 April 2016, M. Cedeño-Sanchez (UCH9545). Ex type: MC66 deposited at HZI.

Notes - Hypoxylon baruense sp. nov. is closely related to $H$. subgilvum, but can be differentiated as it has a smooth perispore indehiscent in $10 \% \mathrm{KOH}$ and larger ascospores. There is only one other species of Hypoxylon with indehiscent perispore reported in Panama, $H$. cinnabarinum, but $H$. baruense differs from this species by having rust and blood colored stromata surface and $\mathrm{KOH}$ - extractable pigments with greenish yellow or luteous. In addition, $H$. subgilvum contains mitorubrins as major components but is lacking BNT (Hellwig et al. 2005).

Hypoxylon bellicolor M. Cedeño-Sanchez, L. Wendt \& L.C. Mejía, sp. nov.

Fig. 3

Mycobank number: MB 832716; Facesoffungi number: FoF 07188

Etymology - Lat. "bellus": pretty, color (referring to the color of the stromata).

Stromata - effused-pulvinate, sessile, with conspicuous perithecial mounds, $0.4-1.4 \mathrm{~cm} \mathrm{x}$ $0.4-0.7 \mathrm{~cm}(\mathrm{n}=4)$; surface Fulvous (43), Rust (39); with orange granules beneath the surface; with $\mathrm{KOH}$-extractable pigments Sienna (8), Luteous (12). Perithecia: obovoid, $0.1-0.2 \mathrm{~mm}$ broad $\mathrm{x}$ $0.2-0.3 \mathrm{~mm}$ high $(\mathrm{n}=6)$. Ostioles: lower than the stromatal surface. Asci: not seen. Ascospores: dark brown, unicellular, ellipsoid, 10-12 x 4-6 $\mu \mathrm{m}(\mathrm{n}=13)$, with germ slit less than spore-length; perispore dehiscent in $10 \% \mathrm{KOH}$, smooth. 
Culture characteristics - on PDA covering a $60 \mathrm{~mm}$ Petri dish in 4 weeks, mycelium white above, reverse dark brown, with concentric zones. No asexual morph observed in the different culture media used i.e. PDA, 2\% MEA, V8 agar, Oatmeal agar and potato carrot agar.
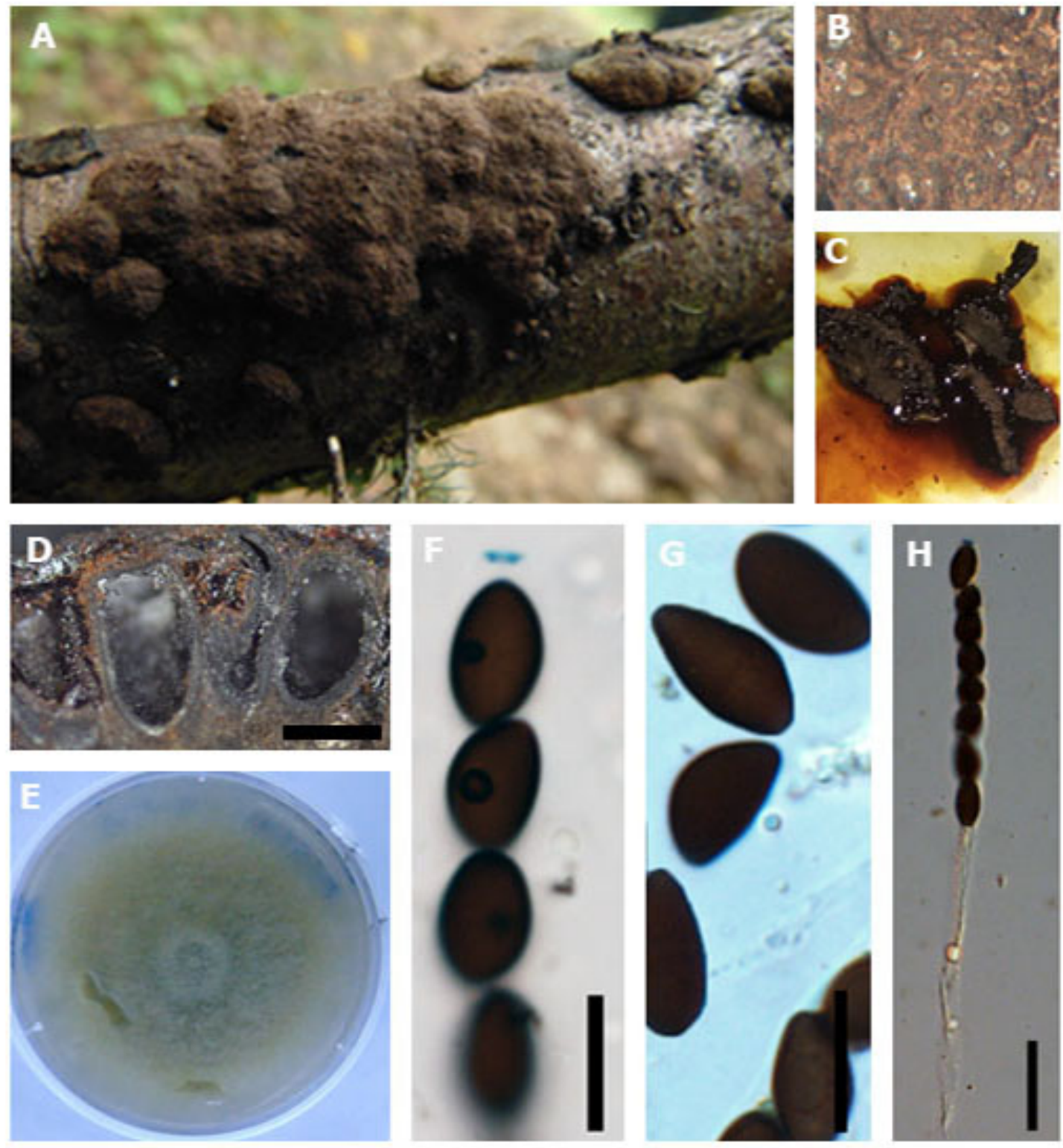

Figure 2 - Hypoxylon baruense sp. nov. (Holotype UCH9545). a Stroma. b Ostioles. c KOHextractable stromatal pigments. d Perithecia (cross section). e PDA culture. f Amyloid apical apparatus. g Ascospores. $\mathrm{h}$ Ascus. Scale bars: $\mathrm{d}=0.3 \mathrm{~mm}, \mathrm{e}=10 \mu \mathrm{m}, \mathrm{g}=10 \mu \mathrm{m}, \mathrm{f}=20 \mu \mathrm{m}$.

Secondary metabolites - Stromata contain BNT in small amounts and otherwise yield little pigments.

Distribution - Panama.

Holotype - Panama, Chiriquí, Bugaba, latitude 09¹4'59.2" longitude 7941'32.8", on dead trunk, 9 February 2016, M. Cedeño (UCH9543). No Ex type culture exists as the culture obtained and used for phylogenetic analyses (MC36) did not survive.

Notes - This species can be distinguished by having the following combination of morphological characters: effused-pulvinate stromata, umbilicate ostioles, and ascospore size 1012 x 4-6 $\mu \mathrm{m}$. Hypoxylon bellicolor, $H$. macrocarpum and $H$. brevisporum have effused-pulvinate stromata, ostioles lower than the stromatal surface and dehiscent perispore in $10 \% \mathrm{KOH}$. However, 
$H$. bellicolor has much larger ascospores (size) than H. brevisporum; and $H$. bellicolor has fulvous stromata and obovoid perithecia while $H$. macrocarpum has violet-purple or vinaceous reddishpurple stromata and ovoid larger perithecia.
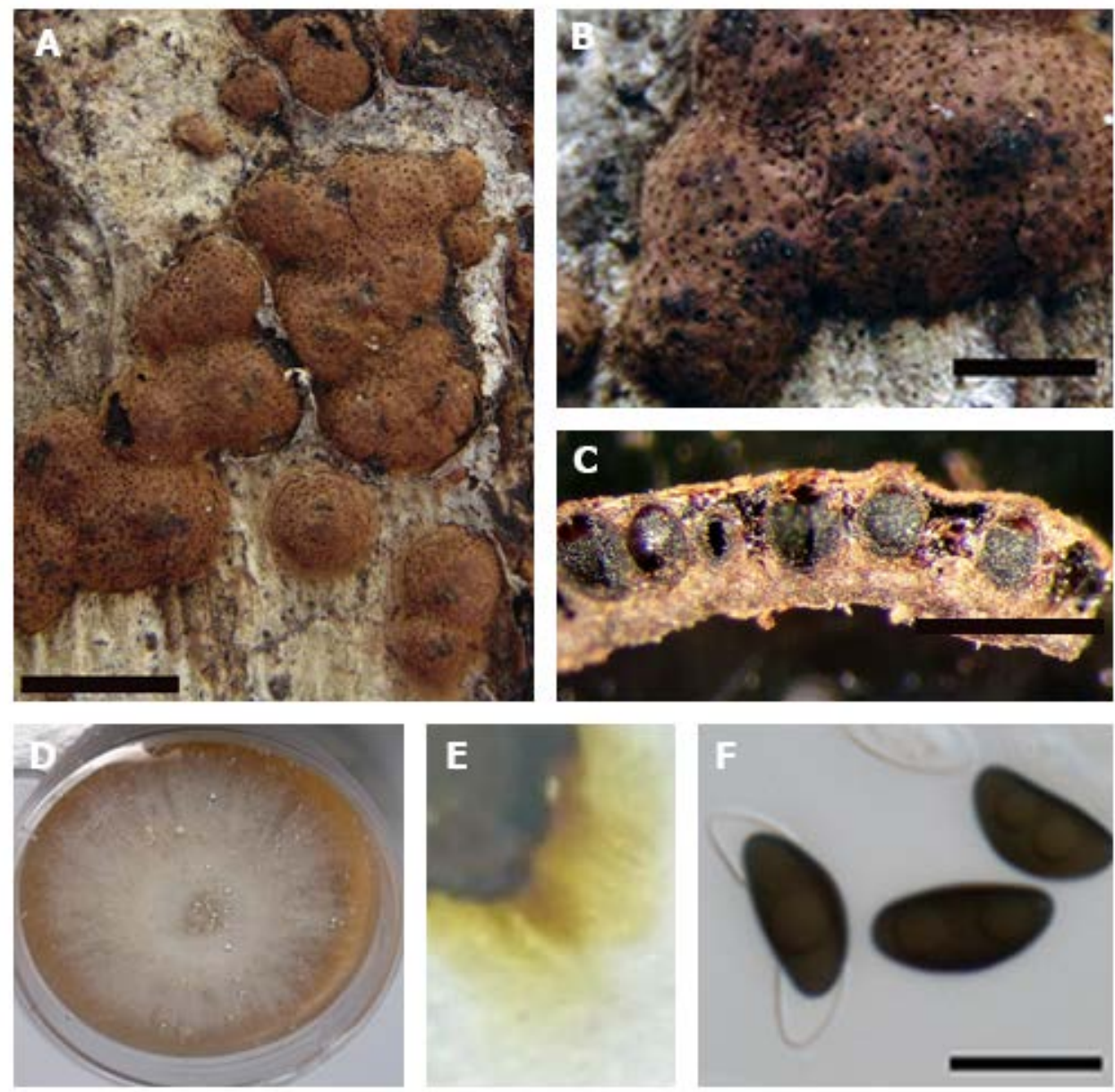

Figure 3 - Hypoxylon bellicolor sp. nov. (Holotype UCH9543). a Stroma. b Ostioles. c Perithecia (cross section). d PDA culture. e KOH-extractable stromatal pigments. f Ascospores with dehiscent perispore in $10 \% \mathrm{KOH}$. Scale bars: $\mathrm{a}=5 \mathrm{~mm}, \mathrm{~b}=2 \mathrm{~mm}, \mathrm{c}=0.5 \mathrm{~mm}, \mathrm{f}=10 \mu \mathrm{m}$.

Hypoxylon sporistriatatunicum M. Cedeño-Sanchez, L. Wendt \& L.C. Mejía, sp. nov.

Fig. 4

Mycobank number: MB 832718; Facesoffungi number: FoF 07187

Etymology: Referring to the striated perispore.

Stromata - glomerate, sessile, with conspicuous perithecial mounds, $0.2-0.3 \mathrm{~cm}$ long x $0.2-$ $0.4 \mathrm{~cm}$ broad ( $\mathrm{n}=15)$; surface Fawn (87); with orange granules beneath the surface; with $\mathrm{KOH}-$ extractable pigments Luteous (12), Sienna (8), Greenish Yellow (18). Perithecia: obovoid, 0.3 $0.4 \mathrm{~mm}$ broad x $0.4-0.5 \mathrm{~mm}$ high $(\mathrm{n}=8)$. Ostioles: slightly higher than the stromatal surface. Asci: 92-140 x 7-9 $\mu \mathrm{m}(\mathrm{n}=18)$, with apical apparatus bluing in Melzer's reagent, 2.7-3 $\mu \mathrm{m}$ long x 0.5$1.1 \mu \mathrm{m}$ broad $(\mathrm{n}=10)$. Ascospores: dark brown, unicellular, ellipsoid, with rounded ends, 10.4-13.2 x 5.4-7.3 $\mu \mathrm{m}(\mathrm{n}=50)$, with germ slit almost the length of the spore; perispore dehiscent in $10 \%$ $\mathrm{KOH}$, with conspicuous coil-like ornamentation.

Culture characteristics: on PDA covering a $60 \mathrm{~mm}$ Petri dish in 4 weeks, mycelium white above, reverse dark brown, with concentric zones. No asexual morph observed in the different culture media used i.e. PDA, 2\% MEA, V8 agar, Oatmeal agar and Potato carrot agar.

Secondary metabolites - Stromata contain hypomiltin as major component and other azaphilones similar to rubiginosin $\mathrm{C}$ as well as BNT as minor components. Macrocarpone A was also detected tentatively. 
Distribution - Panama

Holotype - Panama, Chiriquí, International Park La Amistad, latitude 853'39.4" longitude 82³6'55", on dead trunk, 27 March 2016, M. Cedeño (UCH9542). Ex type culture (MC50), deposited at HZI.

Additional specimen examined - Panama, Chiriquí, Barú Volcano National Park Park, Quetzales trail, latitude 850'50.3" longitude 82³1'39.6", on dead trunk, 23 April 2016, M. Cedeño (UCH9551).
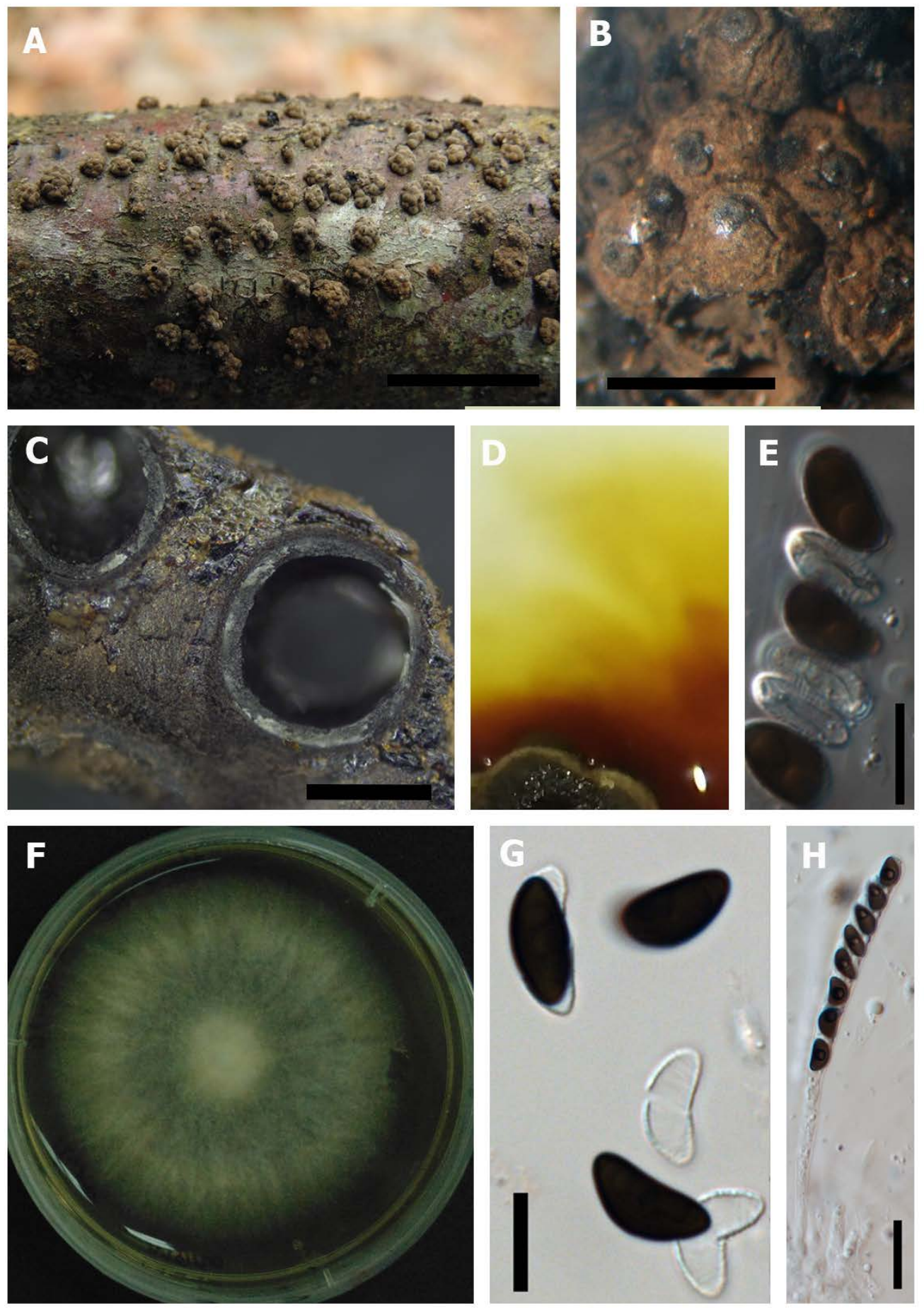

Figure 4 - Hypoxylon sporistriatatunicum sp. nov. (Holotype UCH9542). a Stroma. b Ostioles. c Perithecium cross section. d $\mathrm{KOH}-$ extractable stromal pigments. e Ascospores with striated perispore. $\mathrm{f}$ PDA culture. g Dehiscent perispore in $\mathrm{KOH} \mathrm{10 \% .} \mathrm{h} \mathrm{Asci.} \mathrm{Scale} \mathrm{bar:} \mathrm{a}=1 \mathrm{~cm}, \mathrm{~b}=1$ $\mathrm{mm}, \mathrm{c}=0.2 \mathrm{~mm}, \mathrm{e}=10 \mu \mathrm{m}, \mathrm{g}=10 \mu \mathrm{m}, \mathrm{H}=20 \mu \mathrm{m}$. 
Notes - Hypoxylon sporistriatatunicum sp. nov. is closely related to $H$. shearii var. minor, but differs from this species by presenting hemispherical to spherical stroma, ostioles higher than the surface, and larger ascospores. Additionally, H. sporistriatatunicum has a combination of features that make it different to other species of Hypoxylon including glomerate stromata, ostioles slightly higher than the stromatal surface, dehiscent perispore in $10 \% \mathrm{KOH}$, and conspicuous coil-like ornamentation of the perispore. From a chemotaxonomic point of view, it is interesting that the prevailing component in the stromatal extract (hypomiltin) is also the main metabolite of $H$. perforatum, which also clusters in the same major subclade. $H$. shearii var. minor, the next relative in the phylogenetic tree, was so far not studied by HPLC because the type specimen could not be obtained from the Mexican herbarium (ITCV) on our request and may actually have been lost. However, the typical variety $H$. shearii var. shearii was previously shown to contain mitorubrins (Stadler et al. 2008), and the two varieties share orange pigments, hence it is possible that var. minor also contains similar stromatal metabolites.
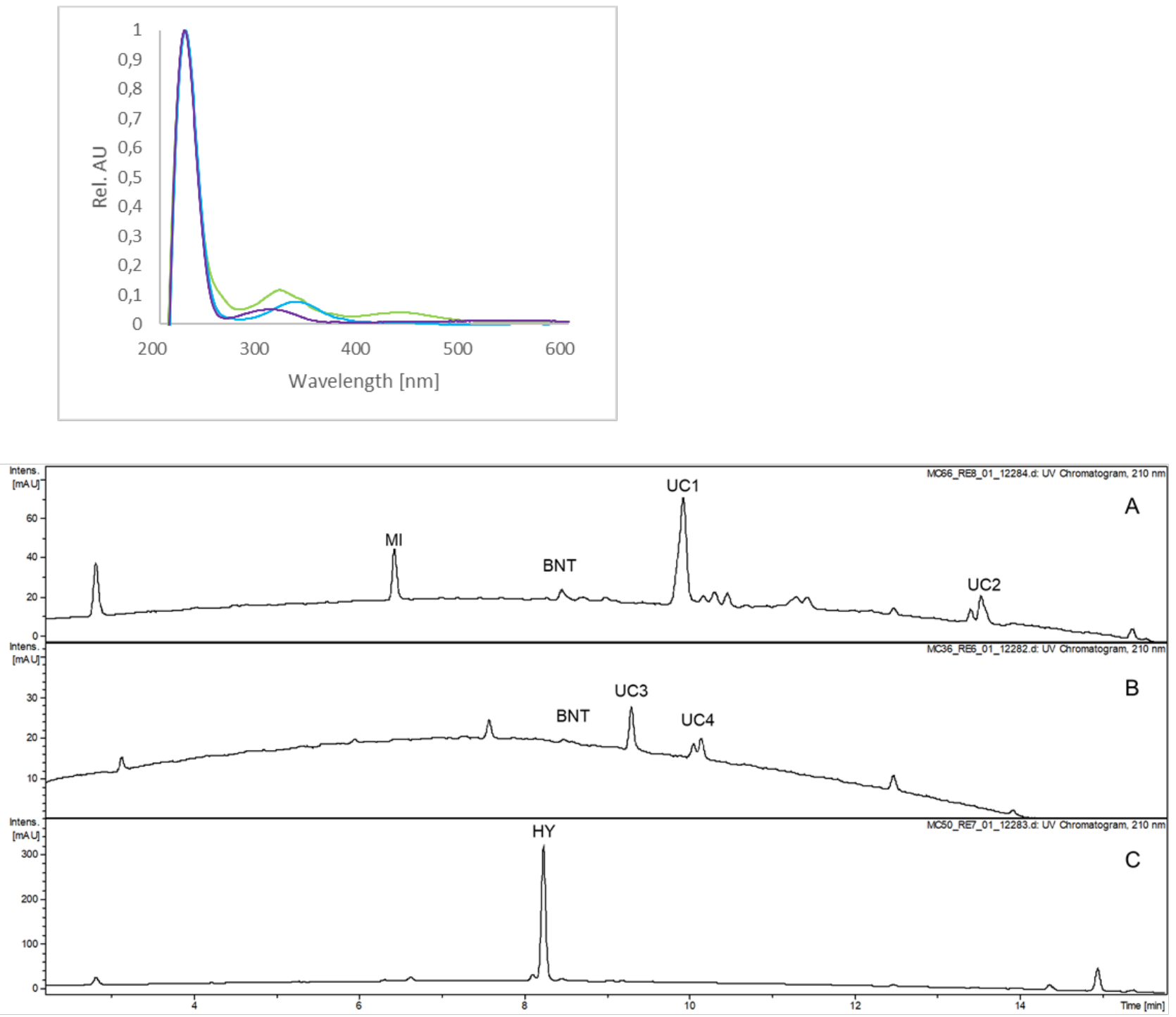

Figure 5 - Above: Normalized UV-Vis chromatograms of unknown compounds UC1, UC2, UC 3 \& 4 from stroma of Hypoxylon baruense sp. nov. (Holotype UCH9545 ex-type MC66) and Hypoxylon bellicolor sp. nov. (Holotype UCH9543 ex-type MC36). Below: HPLC-UV chromatograms $(210 \mathrm{~nm})$ of stromatal methanolic extracts of the holotypes of Hypoxlon baruense (A), H. bellicolor (B) and $H$. sporistriatatunicum (C). Identifiable compounds are BNT (only detectable in traces by HPLC-MS in $H$. belicolor), mitorubrin (MI) and hypomiltin (HY). Unknown compounds detected are labelled with "UC1-4". 


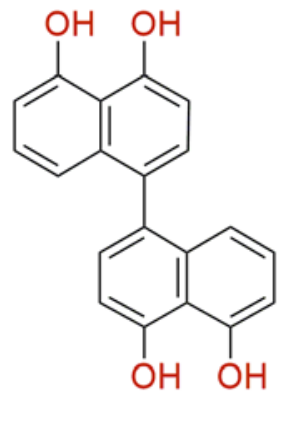<smiles>CC/C=C/C1=CC2=CC(=O)[C@](C)(OC(=O)c3c(C)cc(O)cc3O)C(=O)C2=CO1</smiles>

BNT<smiles>CC(=O)OC/C=C/C1CC2=CC(=O)[C@H](OC(=O)c3c(C)cc(O)cc3O)C(=O)C2=CO1</smiles>

Hypomiltin

Figure 6 - Chemical structures of secondary metabolites detected in the new Hypoxylon species from Panama, mentioned in Fig. 5.

\section{New reports of Xylariaceae and Hypoxylaceae from Panama}

Amphirosellinia evansii (Læssøe \& Spooner) Y.M. Ju, J.D. Rogers \& H.M. Hsieh, in Ju, Rogers, Hsieh \& Vasilyeva

Stromata: hemispherical, sessile, 1-1-3 mm long x 1-1.3 mm broad ( $\mathrm{n}=10)$; surface brown; the tissue (fungal and host) around the stroma have a stellate pattern. Perithecia: round to obovoid, $0.7-0.9 \mathrm{~mm}$ broad x $0.7-0.9 \mathrm{~mm}$ high $(\mathrm{n}=10)$. Ostioles: higher than the stromatal surface. Asci: $158-247$ x 9-10 $\mu \mathrm{m}(\mathrm{n}=4)$, with apical apparatus bluing in Melzer's reagent, $9-10 \mu \mathrm{m}$ high x 6-7 $\mu \mathrm{m}$ broad ( $\mathrm{n}=11)$. Ascospores: dark brown, unicellular, ellipsoid, 20-22 x 8-10 $\mu \mathrm{m}(\mathrm{n}=14)$, with spiral germ slit running over the whole spore-length; perispore indehiscent in $10 \% \mathrm{KOH}$, smooth.

Culture characteristics: no cultures obtained.

Distribution: Australia, Great Britain, Panama, USA.

Specimens examined: Panama, Chiriquí, La Amistad International Park, latitude 853'46.9" longitude 82³7'1.7", on dead trunk, 27 March 2016, M. Cedeño (UCH9559); latitude 853'39.3" longitude 82³6'57.7", on dead trunk, 27 March 2016, Specimen MC54.

Notes: This species is distinguished by having a spiral-shaped germ slit in the ascospores and forming a star-shaped pattern around the stroma, with host tissue and fungus. These characteristics were observed in the identified specimens.

Hypoxylon cinnabarinum (Henn.) Y.M. Ju \& J.D. Rogers

Stromata: effused-pulvinate, sessile, $1-3 \mathrm{~cm}$ long $\mathrm{x}$ 0.7-1.8 cm broad $(\mathrm{n}=3)$, with conspicuous perithecial mounds; surface Orange (7) on the ostiole side and Saffron (10) in the sterile edges; orange granules beneath the surface and surrounding the perithecia, a line of white granules beneath the perithecia, the tissue below the perithecia black; with $\mathrm{KOH}$-extractable pigments Orange (7). Perithecia: obovoid to tubular, $0.3-0.4 \mathrm{~mm}$ broad x $0.4-0.5 \mathrm{~mm}$ high $(\mathrm{n}=8)$. Ostioles: lower than the stromatal surface. Asci: $144-160 \times 7-10 \mu \mathrm{m}$ broad $(\mathrm{n}=6)$, with apical apparatus bluing in Melzer's reagent, $1 \mu \mathrm{m}$ high x 3-4 $\mu \mathrm{m}$ broad $(\mathrm{n}=7)$. Ascospores: brown to dark brown, unicellular, ellipsoid nearly equilateral, 11-13 x 6-7 $\mu \mathrm{m}(\mathrm{n}=17)$, with germ slit of sporelength; perispore indehiscent in $10 \% \mathrm{KOH}$, smooth.

Colonies: on PDA, white mycelium above, reverse green.

Distribution: Brazil, Mexico, New Zealand, Panama, Puerto Rico, Taiwan, Venezuela. Lectotype is from Brazil and was designated by Ju \& Rogers (1996). However, the culture used in the phylogenetic studies by Hsieh et al. 2005 and the description of the asexual morph by Ju \& Rogers (1996) originated from Mexico. The culture from Mexico was included in the phylogeny presented here and is conspecific with the specimen from Panama (Fig. 1).

Specimens examined: Panama, Chiriquí, Sortová, latitude 08³4'08.9" longitude 82³9'25.9", on dead trunk of Citrus sinensis, 5 August 2016, M. Cedeño (UCH9563, consisting of a dried 
specimen); Divalá, on dead branches of a live tree of Citrus sinensis, 9 November 2016, M. Cedeño (UCH9546).

Notes: This species has nearly equilateral ascospores with perispore frequently indehiscent in $10 \% \mathrm{KOH}$. Based on analyses of morphological characters, Fournier \& Lechat (2015) and Fournier et al. (2015) suggested the possibility of two other species of Hypoxylon that resemble $H$. cinnabarinum i.e. $H$. cf. cinnabarinum sp. 1 and $H$. cf. cinnabarinum sp. 2. However, they suggested that in the absence of complete cultural, molecular, and chemotaxonomic work for all the specimens that they studied, it was better not to segregate $H$. cinnabarinum into different species (Fournier et al. 2015). The specimens here studied fits the description of $H$. cinnabarinum according to Ju \& Rogers (1996) and also the one that Fournier et al. (2015) identified as H. cf. cinnabarinum sp. 1 , so we decided to keep the specimens collected in Panama as part of this study identified as $H$. cinnabarinum in the broad sense.

\section{Hypoxylon howeanum Peck}

Stromata: hemispherical to spherical, sessile, $5.5 \mathrm{~mm}$ long x $4 \mathrm{~mm}$ broad x $2.7 \mathrm{~mm}$ high $(n=6)$, with inconspicuous perithecial mounds; surface color Fulvous (43), Rust (39), with orange granules beneath the surface; the tissue below the perithecia black, homogeneous; with $\mathrm{KOH}-$ extractable pigments Orange (7) or Rust (39). Perithecia: obovoid, $0.2-0.3 \mathrm{~mm}$ broad x $0.4 \mathrm{~mm}$ high $(n=10)$. Ostioles: lower than the stromatal surface. Asci: 103-150 x 4.5-6 $\mu \mathrm{m}(\mathrm{n}=5)$, with apical apparatus bluing in Melzer's reagent, $\mu \mathrm{m} 0.2 .8-0.3$ high x $1.5-1.8 \mu \mathrm{m}$ broad $(\mathrm{n}=8)$. Ascospores: brown, unicellular, ellipsoid, with narrowly rounded ends, 8-9 x 4-5 $\mu \mathrm{m}(\mathrm{n}=17)$, with germ slit spore-length; perispore dehiscent in $10 \% \mathrm{KOH}$, smooth. center.

Culture characteristics: on PDA, mycelium white above, reverse greenish pigmentation in the

Distribution: Australia, Czech Republic, France, Germany, India, Italy, Iran, Japan, Mexico, New Zealand, Norway, Panama, Poland, Spain, South Africa, Turkey, United Kingdom, USA. Hypoxylon howeanum occurs on a wide variety of angiosperm hosts in Europe, but almost never on European beech, Fagus sylvatica, where the sister species $H$. fragiforme is predominant.

Specimens examined: Panama, Chiriquí, Barú Volcano National Park, Quetzales Trail, latitude 8'50'50.4" longitude 82³1'39.5", on dead branch of Alnus acuminata., 23 April 2016, M. Cedeño (UCH9565); latitude 8०50'46.7" longitude 82 $31^{\prime} 50.9^{\prime \prime}$, on dead branch of Alnus acuminata., 23 April 2016, Cedeño MC65.

Notes: This species is characterized by hemispherical to spherical stromata, and ostioles lower than the stromatal surface. Hypoxylon howeanum is similar to $\mathrm{H}$. fragiforme, the type species of the genus, but differs in having smaller ascospores. In addition, its stromata can colonize a broad variety of hosts (including Acer and various species of Salicaceae and Betulaceae), while $H$. fragiforme is mainly restricted to Fagus in the temperate Northern hemisphere. The species was found growing on Alnus acuminata at 2,500 m.a.s.l. and which is native to Panama.

Stilbohypoxylon quisquiliarum (Mont.) J. D. Rogers \& Y.-M. Ju

Stromata: subglobose to globose, sessile, $0.8-1 \mathrm{~mm}$ high x $1-1.3 \mathrm{~mm}$ broad, black surface, with yellow scales (no too much visible). Ostioles: higher than the stromatal surface, papillate Asci: not found. Ascospores: dark brown, unicellular, 26-31 x 12-15 $\mu \mathrm{m}(\mathrm{n}=8)$, inequilaterally ellipsoidal, with spiral germ slit running over the whole spore length; perispore indehiscent in $10 \%$ $\mathrm{KOH}$, smooth.

Culture characteristics: no culture obtained.

Distribution: Brazil, Costa Rica, Panama, Singapore.

Specimen examined: Panama, Panama, Soberania National Park, pipeline rout trail, on dead trunk, 8 August 2015, M. Cedeño (UCH9547).

Notes: This species is distinguished by the presence of yellow scales in mature stromata, and germinal line of the length of the spore and in spiral (Petrini 2004). The germ slit was clearly 
observed in the specimen, but the scales were not clear. It differs from S. macrosporum by having smaller ascospores.

\section{Additional specimens of Hypoxylon collected in this study}

\section{Hypoxylon fendleri Berk. ex. Cooke}

Stromata: effused-pulvinate, sessile, $3 \mathrm{~cm}$ long x $0.7 \mathrm{~cm}$ broad $(\mathrm{n}=1)$, with inconspicuous perithecial mounds; surface color Fulvous (43), Rust (39), orange granules beneath surface; with $\mathrm{KOH}$-extractable pigments Orange (7) or Rust (39). Ostioles: lower than the stromatal surface. Asci: with apical apparatus bluing in Melzer's iodine reagent, $0.6-1 \mu \mathrm{m}$ high x $1.8-2.2 \mu \mathrm{m}$ broad $(\mathrm{n}=9)$. Ascospores: brown, unicellular, ellipsoid, smooth, 8.9-10.2 x 3.9-4.7 $\mu \mathrm{m}(\mathrm{n}=10)$, with straight germ slit spore-length; perispore dehiscent in $10 \% \mathrm{KOH}$, smooth.

Culture characteristics: on PDA white mycelium, reverse cream color, darkness in the center and light in the edge.

Distribution: Pantropical.

Specimen examined: Panama, Chiriquí, Sortová, on dead trunk, 1 January 2016, M. Cedeño (UCH9552).

Notes: This fungus is very common throughout the tropics. In Ju \& Rogers (1996) it is mentioned that Hypoxylon fendleri differs from $H$. trugodes and $H$. crocopeplum by the color of stromal pigments extracted with $10 \% \mathrm{KOH}$. The specimen treated in this work showed the typical morphological characteristics of $H$. fendleri and this was also supported by the phylogenetic analysis.

\section{Hypoxylon haematostroma Mont.}

Stromata: plane to effused-pulvinate, sessile, $0.3-1.7 \mathrm{~cm}$ long x $0.2-1.3 \mathrm{~cm}$ broad x $0.2 \mathrm{~cm}$ thick, with inconspicuous perithecial mounds; surface Sienna (8); with $\mathrm{KOH}$-extractable pigments Orange (7), Scarlet (5). Perithecia: long tubular, $0.5 \mathrm{~mm}$ broad x $2 \mathrm{~mm}$ high $(\mathrm{n}=11)$. Ostioles: lower than the stromatal surface. Asci: not found. Ascospores: brown, unicellular, ellipsoid, smooth, 15-18 x 6-7 $\mu \mathrm{m}(\mathrm{n}=11)$, with straight germ slit spore-length; perispore dehiscent in $10 \%$ $\mathrm{KOH}$, smooth.

Culture characteristics: on PDA white mycelium, reverse greenish color, with zones with concentric.

Distribution: Pantropical

Specimen examined: Panama, Panama, Soberania National Park, El Charco trail, on dead dicotyledonous trunk, 30 January 2016, M. Cedeño (UCH9555).

Notes: This species is distinctive among species of Hypoxylon by having tubular perithecia and red or orange granules below the stromatal surface (Ju \& Rogers 1996). Both morphological characteristics were present in the specimen examined. Additionally, the species have brown to dark brown ascospores with a perispore dehiscent in $10 \% \mathrm{KOH}$, nevertheless, the size of ascospores is variable according to Fournier et al. (2015) ranging from $12.5-18$ x $5.9-9 \mu \mathrm{m}$.

\section{Key to Hypoxylon species from Panama}

1a. Perispore dehiscent in $10 \% \mathrm{KOH}$..... .5

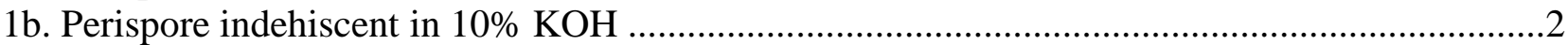

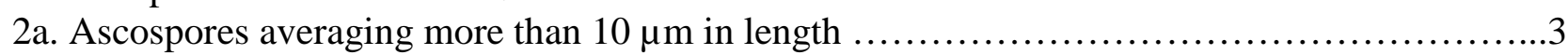

2b. Ascospores averaging less than $10 \mu \mathrm{m}$ in length ........................................

3a. Ascospores 10-15 x 5-7.6 $\mu \mathrm{m}$, with $\mathrm{KOH}$-extractable pigments (greenish yellow or luteous)

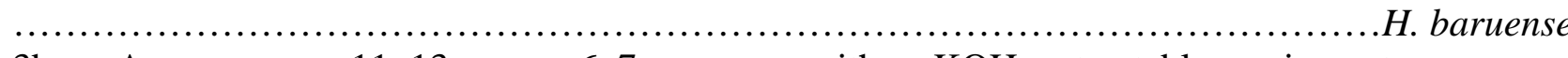
3b. Ascospores 11-13 x 6-7 $\mu \mathrm{m}$, with $\mathrm{KOH}-$ extractable pigments orange .................................................................... cinnabarinum 
4a. Perithecia obovoid; KOH-extractable pigments grayish sepia; with faint germ slit H. dieckmannii 4b. Perithecia tubular to long tubular; $\mathrm{KOH}-$ extractable pigments greenish yellow, dull green or dark green; and straight germ slit .H. investiens 5a. Apical apparatus bluing to lightly bluing in Melzer's iodine reagent ........................6 5b. Apical apparatus not bluing in Melzer's iodine reagent; ascospores 9-11 x 4.5-5.5 $\mu \mathrm{m}$ with perispore with very conspicuous coil-like ornamentation; perithecia spherical ......H. pelliculosum 6a. $\mathrm{KOH}-$ extractable pigments greenish yellow, orange, scarlet, rust, luteous, sienna, bay .........7 6b. $\mathrm{KOH}-$ extractable pigments with other than above colors ................................13 7a. Stromata hemispherical to spherical, sometimes effused-pulvinate, $\mathrm{KOH}$-extractable pigments

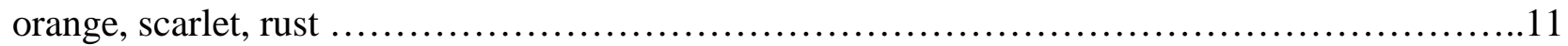

7b. Stromata effused-pulvinate or plane with $\mathrm{KOH}$-extractable pigments orange ..................8 8a. Sigmoid germ slit, ascospores 9-12 x 4-5.5 $\mu \mathrm{m}$; perithecia spherical, obovoid, ostioles lower

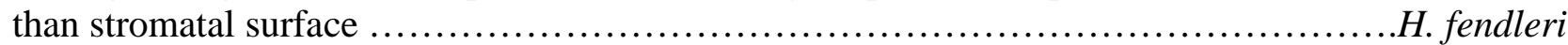
8b. Straight to slightly sigmoid germ slit; perithecia spherical, obovoid, tubular to long tubular ...9 9a. Straight germ slit; perithecia spherical to obovoid; stromata effused-pulvinate, pulvinate or even semispherical; ascospores $9-12$ x $4-5.5 \mu \mathrm{m}$................................. rubiginosum 9b. Straight to slightly sigmoid germ slit; perithecia obovoid, tubular to long tubular .... 10 10a. Straight to slightly sigmoid germ slit; ascospores 9.5-15 x 4-7 $\mu \mathrm{m}$; perithecia spherical, obovoid to long tubular, ostiloles lower than or same level as the stromatal surface $H$. crocopeplum 10b. Straight to slightly sigmoid germ slit; ascospores $7-11 \times 3.5-5 \mu \mathrm{m}$; perithecia obovoid to tubular, ostioles lower than the stromatal surface ................................... subgilvum 11a. Perithecia long tubular; stromata semispherical to effused-pulvinate, $\mathrm{KOH}$-extractable pigments orange, scarlet; ascospores 13.5-18 x 7-8 $\mu \mathrm{m}$

.H. haematostroma 11b. Perispore obovoid, stromata semispherical to spherical, ascospores less than $13 \mu \mathrm{m} . \ldots \ldots . .12$ 12a. Ascospores 8-9 x 4-5 $\mu \mathrm{m}$, with smooth perispore, apical apparatus bluing in Melzer's iodine reagent $0.28-0.3 \times 1.5-1.8 \mu \mathrm{m}$; $\mathrm{KOH}-$ extractable pigments rust, sienna ... H. howeanum 12b. Ascospores 11-13 x 6-7 $\mu \mathrm{m}$, with conspicuous coil-like ornamentation perispore, with apical apparatus bluing in Melzer's iodine reagent 2.7-3x0.5-1.1 $\mu \mathrm{m} ; \mathrm{KOH}$-extractable pigments

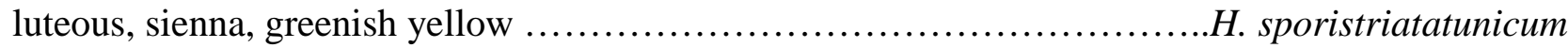
13a. Ascospores light brown to brown, perispore smooth, ascospores 7-9 x 3-4 $\mu \mathrm{m}$ with slightly oblique to sigmoid germ slit ................................................ hypomiltum 13b. Ascospores brown to dark brown, perispore smooth or with inconspicuous coil-like ornamentation ......................................................................... 14

14a. Straight to slightly sigmoid germ slit, stromata effused-pulvinate ......................15 14b. Sigmoid germ slit, stromata usually hemispherical to pulvinate, sometimes effused-pulvinate, ascospores 8-20 x 4-8 $\mu \mathrm{m}$ .H. fuscum 15a. Conspicuous perithecial mounds, perithecia obovoid; ascospores 10-12 x 4-6 $\mu \mathrm{m}$ H. bellicolor

15b. Inconspicuous perithecial mounds, perithecia obovoid, tubular, long tubular ..16 16a. Ascospores brown, straight to slightly sigmoid germ slit, $\mathrm{KOH}$-extractable pigments dark livid ..H. lividipigmentum

16b. Ascospores brown to dark brown, slightly sigmoid germ slit, KOH-extractable pigments of different colors ......................................................................... 17a. KOH-extractable pigments amber, isabelline, olivaceous, gray alivaceous, greenish olivaceous; ascospores $8.5-13.5$ x 4-6 $\mu \mathrm{m}$.................................... anthochroum 17b. KOH-extractable pigments amber, yellow; ascospores 8-11 x 3.5-4.5 $\mu \mathrm{m}$.........

\section{Discussion}

Morphological observations and analyses of DNA sequence data of Xylariales specimens collected in Panama allowed us to identify three new species of Hypoxylon as well as to document four new records of this genus and three new records of Xylariaceae for the country. The phylogeny 
of Hypoxylon obtained in this study based on the concatenated analysis of $\beta$-tubulin and ITS loci (Fig. 1) is in general agreement with a recently published phylogeny of Hypoxylon based on multilocus data (Wendt et al. 2018).

The species treated in this study showed a restricted altitudinal distribution, for example, $H$. bellicolor sp. nov., $H$. cinnabarinum and $S$. quisquiliarum were collected only at lowland (700 m.a.s.l. or lower). In contrast Amphirosellinia evansii, H. sporistriatatunicum sp. nov., H. baruense sp. nov., and $H$. howeanum were observed in the highlands (1500 m.a.s.l. or higher) of Chiriquí Province. In general, the species observed in this study were found only in one site, except $H$. sporistriatatunicum sp. nov., which was collected in La Amistad International Park and in the Barú Volcano National Park, both parks located in the province of Chiriquí. Our data suggest that the distribution of Hypoxylon species in Panama is restricted either by locality or elevation, but further studies are necessary to confirm these observations. The distribution of the species could be also related to the type of forest or life zone, for example, La Amistad International Park and the Barú Volcano National Park have six of the twelve life zones of Panama. The Barú Volcano National Park presents two unique life zones in the country: montane very wet forest and low montane wet forest (MiAMBIENTE 2016), unlike Soberania National Park that is predominantly tropical wet forest, and Sortová and Concepción which are premontane very wet forests.

Specimens treated in this study were collected on decomposing dead trunks or dead branches and $H$. cinnabarinum was collected growing on a dead branch but still attached to a living tree of Citrus sinensis, a new host of this species. This species has been found on the bark of dead branches and trunks of unidentified hosts (Ju \& Rogers 1996, Fournier et al. 2015, Fournier \& Lechat 2015), as well as on Beilschmiedia tawa and an unidentified Nothofagus species (Ju \& Rogers 1996).

This study increased the numbers of known species of Hypoxylaceae of Panama from 30 to 35 and Xylariaceae from 45 to 47 . Given the facts that $i$ ) several new species were recently reported from this geographic area and ii) many other taxa have been known from the neighbour countries of Panama during the past century, additional studies on the systematics and ecology of these families are called for. Considering the reported biological activities of fungi of the Xylariales (Helaly et al. 2018), including antimicrobials or virulence factors such as the azaphilones and mitorubrinol acetate to be produced by species described here, it is possible that new species from this order might be potential sources of new compounds for biotechnological applications. This information can be of value to promote more studies and in situ conservation efforts of the habitats and diversity of these fungi.

\section{Acknowledgements}

This project received funding support from the National Secretariat of Science and Technology of Panama (SENACYT, grants ITE11-19, APY-NI-2015-13). LCM also received support from the SENACYT SNI program and the project Biobanco Panamá sponsored by MiAMBIENTE (Convenio UFISI No. 003-49-20199). We are deeply indebted to Dr. Jack D. Rogers for looking at our specimens and helping with their identification as well as for his insightful comments. Lucile Wendt is grateful for a PhD stipend from the Hannover School for Biomolecular Drug Research (HSBDR). We also thank the Panamanian Ministry of the Environment (MiAMBIENTE) for granting the specimens collecting permit to do this research and for protecting the environment where the species reported here occur.

\section{References}

Benson DA, Cavanaugh M, Clark K, Karsch-Mizrachi I et al. 2013 - GenBank. Nucleic Acids Research 41, D36-D42.

Bills GF, Gonzalez-Menendez V, Martın J, Platas G et al. 2012 - Hypoxylon pulicicidum sp. nov. (Ascomycota, Xylariales), a pantropical insecticide-producing endophyte. PLoS One 7:e46687. 
Carmona A, Fournier J, Williams C, Piepenbring M. 2009 - New records of Xylariaceae from Panama. North American Fungi 4, 1-11.

Castresana J. 2000 - Selection ofconserved blocks from multiple alignments for their use in phylogenetic analysis. Molecular Biolology and Evolution 17:540-552

Daranagama DA, Hyde KD, Sir EB, Thambugala KM et al. 2018 - Towards a natural classification and backbone tree for Graphostromataceae, Hypoxylaceae, Lopadostomataceae and Xylariaceae. Fungal Diversity 88, 1-165.

Dayarathne MC, Maharachchikumbura SSN, Jones EBG, Goonasekara ID et al. 2017 Neophyllachora gen nov. Phyllachorales), three new species of Phyllachora from Poaceae and resurrection of Polystigmataceae (Xylariales). Mycosphere 8: 1598-1625.

Darriba D, Taboada GL, Doallo R, Posada D. 2012 - jModelTest 2: more models, new heuristics and parallel computing. Nature Methods 9, 772.

De Long Q, Liu LL, Zhang X, Wen TC et al. 2019 - Contributions to species of Xylariales in China-1. Durotheca species. Mycological Progress 18(3), 495-510.

Dennis RWG. 1956 - Some Xylarias of tropical America. Kew Bulletin 11, 401-444.

Dennis RWG. 1970 - Fungus flora of Venezuela and adjacent countries. Kew Bulletin add. Series 3, Royal Botanic Gardens, Kew, 531 pp.

Fournier J, Lechat C, Courtecuisse R. 2015 - The genus Hypoxylon (Xylariaceae) in Guadeloupe and Martinique (French West Indies). Ascomycete.org 7, 145-212.

Fournier J, Lechat C. 2015 - New, rare and unsettled species of Hypoxylon (Xylariaceae) from French Guiana. Ascomycete.org 7, 63-96.

Friebes G, Wendelin I. 2016 - Studies on Hypoxylon ferrugineum (Xylariaceae), a rarely reported species collected in the urban area of Graz (Austria). Ascomycete.org 8, 83-90.

Helaly SE, Thongbai B, Stadler M. 2018 - Diversity of biologically active secondary metabolites from endophytic and saprotrophic fungi of the ascomycete order Xylariales. Natural Product Reports 35, 992-1014.

Hellwig V, Ju YM, Rogers JD, Fournier J, Stadler M. 2005 - Hypomiltin, a novel azaphilone from Hypoxylon hypomiltum, and chemotypes in Hypoxylon sect. Hypoxylon as inferred from analytical HPLC profiling. Mycological Progress 4, 39-54.

Hongsanan S, Maharachchikumbura SSN, Hyde KD, Samarakoon MC et al. 2017 - An updated phylogeny of Sordariomycetes based on phylogenetic and molecular clock evidence. Fungal Diversity 84, 25-41.

Hsieh HM, Ju YM, Rogers JD. 2005 - Molecular phylogeny of Hypoxylon and closely related genera. Mycologia 97, 844-865.

Hyde KD, Norphanphoun C, Maharachchikumbura SSN, Bhat DJ et al. 2020 - Refined families of Sordariomycetes. Mycosphere 11, 305-1059

Ju YM, Rogers JD. 1996 - A revision of the genus Hypoxylon. Mycologia Memoir n 20. APS Press, St. Paul, 365 pp.

Katoh M, Kuma M. 2002 - MAFFT: a novel method for rapid multiple sequence alignment based on fast Fourier transform. Nucleic Acids Research 30, 3059-3066

Kearse M, Moir R, Wilson A, Stones-Havas S et al. 2012 - Geneious basic: an integrated and extendable desktop software platform for the organization and analysis of sequence data. Bioinformatics 28, 1647-1649.

Kuhnert E, Fournier J, Peršoh D, Luangsa-ard JJD, Stadler M. 2014 - New Hypoxylon species from Martinique and new evidence on the molecular phylogeny of Hypoxylon based on ITS rDNA and $\beta$-tubulin data. Fungal Diversity 64, 181-203.

Kuhnert E, Surup F, Sir EB, Lambert C et al. 2015 - Lenormandins A - G, new azaphilones from Hypoxylon lenormandii and Hypoxylon jaklitschii sp. nov., recognised by chemotaxonomic data. Fungal Diversity 71, 165-184.

Kuhnert E, Sir EB, Lambert C, Hyde KD et al. 2017 - Phylogenetic and chemotaxonomic resolution of the genus Annulohypoxylon (Xylariaceae) including four new species. Fungal Diversity 85, 1-43 
Lambert C, Wendt L, Hladki AI, Stadler M, Sir EB. 2019 - Hypomontagnella (Hypoxylaceae): a new genus segregated from Hypoxylon by a polyphasic taxonomic approach. Mycological Progress 18, 187-201.

Li JF, Phookamsak R, Jeewon R, Tibpromma S et al. 2017 - Establishment of Zygosporiaceae fam. nov. (Xylariales, Sordariomycetes) based on rDNA sequence data to accommodate Zygosporium. Mycosphere 8, 1855-1868

Mejía LC, Castlebury LA, Rossman AY, Sogonov MV, White JF. 2008 - Phylogenetic Placement and taxonomic review of the genus Cryptosporella and its synonyms Ophiovalsa and Winterella (Gnomoniaceae, Diaporthales). Mycological Research 112, 23-35.

MiAMBIENTE. 2016 - (Ministerio de Ambiente de Panamá) Plan de Uso Público Parque Nacional Volcán Barú. Gaceta Oficial 28075a. Gobierno de Panamá.

O’Donnell K, Cigelnik E. 1997 - Two divergent intragenomic rDNA ITS2 types within a monophyletic lineage of the fungus Fusarium are nonorthologous. Molecular Phylogenetics and Evolution 7, 103-116.

Petrini LE. 2004 - A revision of the genus Stilbohypoxlon (Xylariaceae). Sydowia 56, 51-71.

Piepenbring M, Hofmann TA, Unterseher M, Kost G. 2012 - Species richness of plants and fungi in western Panama: towards a fungal inventory in the tropics. Biodiversity and Conservation 21, 2181-2193.

Piepenbring M. 2013 - Fungi of Panama, Smithsonian Tropical Research Institute. http://biogeodb.stri.si.edu/fungi (accessed 9 Dec 2019).

Platas G, Gonzalez V, Collado J, Martin J et al. 2009 - Ascription of poorly defined taxa to taxonomic entities using molecular phylogenies: a case study on Nodulisporium sp. producers of nodulisporic acid. Mycotaxon 109, 443-460.

Rayner RW. 1970 - A mycological colour chart. Commonwealth Mycological Institute, Kew and British Mycological Society.

Sir EB, Kuhnert E, Surup F, Hyde KD, Stadler M. 2015 - Discovery of new mitorubrin derivatives from Hypoxylon fulvo-sulphureum sp. nov. (Ascomycota, Xylariales). Mycological Progress, 14(5), 28.

Sir EB, Kuhnert E, Lambert C, Hladki A et al. 2016a - New species and reports of Hypoxylon from Argentina recognized by a polyphasic approach. Mycological Progress 15, 1-19.

Sir EB, Lambert C, Wendt L, Hladki AI et al. 2016b - A new species of Daldinia (Xylariaceae) from the Argentine subtropical montane forest. Mycosphere 7(9):1378-1388.

Sir EB, Becker K, Lambert C, Bills GF, Kuhnert E. 2019 - Observations on Texas hypoxylons, including two new Hypoxylon species and widespread environmental isolates of the $H$. croceum complex identified by polyphasic approach. Mycologia 11, 832-856.

Stadler M, Fournier J, Beltrán-Tejera E, Granmo A. 2008 - The "red Hypoxylons” of the temperate and subtropical Northern Hemisphere. North American Fungi 3, 73-125.

Stadler M, Kuhnert E, Peršoh D, Fournier J. 2013 - The Xylariaceae as model example for a unified nomenclature following the "One Fungus- One Name” (1F1N) Concept. Mycology 4, $5-21$

Stamatakis A. 2006 - RAxML-VI-HPC: maximum likelihood-based phylogenetic analyses with thousands of taxa and mixed models. Bioinformatics 22, 2688-2690

Stamatakis A. 2014 - RAxML version 8: a tool for phylogenetic analysis and post-analysis of large phylogenies. Bioinformatics 30:1312-1313

Stamatakis A, Alachiotis N. 2010 - Time and memory efficient likelihood-based tree searches on phylogenomic alignments with missing data. Bioinformatics 26, i132-i139

Standley PC. 1933 - The flora of Barro Colorado Island, Panama. Harvard University, Contributions from the Arnold Arboretum 5, 178 pp.

Surup F, Narmani A, Wendt L, Pfütze S, Kretz R, Becker K, Menbrivès C, Giosa A, Elliott M, Petit C, Rohde M, Stadler M. 2018 - Identification of fungal fossils and novel azaphilone pigments in ancient carbonised specimens of Hypoxylon fragiforme from forest soils of Châtillon-surSeine (Burgundy). Fungal Diversity 92, 345-356. 
Talavera G, Castresana J. 2007 - Improvement of phylogenies after removing divergent and ambiguously aligned blocks from protein sequence alignments. Systematic Biology 56, 564577

Triebel D, Peršoh D, Wollweber H, Stadler M. 2005 - Phylogenetic relationships among Daldinia, Entonaema and Hypoxylon as inferred from ITS nrDNA sequences. Nova Hedwigia 80, 2543.

Wendt L, Sir EB, Kuhnert E, Heitkämper S et al. 2018 - Resurrection and emendation of the Hypoxylaceae, recognised from a multi-gene genealogy of the Xylariales. Mycological Progress 17, 115-154.

Weston WH. 1933 - The fungi of Barro Colorado. Scientific Monthly 36:387-407. 